CHRISTIAN D. SCHUNN \& ELI M. SILK

\title{
1. LEARNING THEORIES FOR ENGINEERING AND TECHNOLOGY EDUCATION
}

\author{
INTRODUCTION
}

Optimizing technical systems depends on scientifically grounded models of system performance. Similarly, the development of engineering and technology education systems fruitfully builds upon relevant learning theories. Engineering and technology involve complex skills and concepts embedded in rich contexts. We review learning theories particularly appropriate for supporting learning of such complex concepts in rich contexts, drawing heavily on information processing, distributed cognition and cognitive apprenticeship.

\section{OVERVIEW}

The goal of this chapter is to articulate ways in which contemporary learning theories drawn from the learning sciences can enhance Engineering and Technology Education (ETE). We believe that ETE has much to gain by grounding research, instructional innovation and evaluation in existing theoretical frameworks. Connecting to theory helps guide instructional designers in the construction of learning environments that are likely to be effective as they build on the scientific work encapsulated in well-established learning theories and they are also then able to contribute further to what is known in ETE disciplines by refining and expanding on those theories.

But connecting to learning sciences theory is difficult for many experienced engineers and engineering/technology educators who seek involvement in education research, but who were not trained in a social science such as psychology or education (Borrego, 2007). To that end, this chapter intends to explore a number of contemporary learning theories that could serve to ground ETE research, design and evaluation. Although we cannot possibly cover all such learning theories, the ones we have chosen may be particularly useful to the work of ETE in which students must learn complex skills and concepts and to use those concepts adaptively in rich contexts.

The chapter is organized around the following two questions:

- Goals: What is ETE as something to be learned?

- Theories: What are some currently influential learning theories that could be applied to ETE?

\section{ENGINEERING AND TECHNOLOGY EDUCATION GOALS}

In thinking about learning theories that may be relevant for ETE, it is important to be explicit about the outcomes that educators would like to see in their students. 
There are two dimensions to consider with respect to ETE. The first dimension is that ETE naturally involves elements of science, technology, engineering and mathematics (STEM). While technology and engineering elements are clearly the most central, they inevitably draw upon science and mathematics at various points, and the design of effective ETE environments should take those connections into account.

Second, there is the question of what fundamental form the elements to be learned take. Since the days of behaviorist learning theories, it has been clear that competent activity in a domain consists of many individual components, each of which must be acquired and developed through experience (Thorndike, 1913)addition and multiplication, for example, are separate math skills, each requiring their own practice. This need for decomposition of learning goals and practice on the components continues to receive theoretical and empirical support (Singley \& Anderson, 1989; Anderson, Bothell, Byrne \& Lebiere, 2004). However, developments in education, cognitive psychology and neuroscience after the days of behaviorism have shown that there is more to learn than just skills (or stimulusresponse associations in the language of behaviorism) and further that different kinds of learning involve different methods. For example, procedures and concepts rely on different brain areas for learning (Knowlton, Mangels \& Squire, 1996); procedures become less introspectable with practice whereas concepts become more introspectable; and procedures are most robust but least flexible when automatized whereas reasoning is generally more flexible but requires conscious control (Anderson, Fincham \& Douglass, 1997). Both are important for developing expertise in a domain.

In engineering terms, a solving a problem in a domain involves a complex system requiring many skills, concepts and other competencies rather than just a simple list of skills. Here is a division that was first developed in mathematics education (Kilpatrick, Swafford \& Findell, 2001) that could be applied productively to ETE. Success appears to require all five elements:

- Procedural fluency - skill in carrying out procedures flexibly, accurately, efficiently and appropriately. This would include the use of tools, models and mathematics in technology/engineering problem-solving.

- Conceptual understanding - explicit comprehension of relevant concepts from engineering, technology, science and mathematics, understanding what possible operations are available and why they work, and an understanding of the relationships between concepts and operations.

- Strategic competence - ability to formulate, represent and solve complex STEM problems.

- Adaptive reasoning - capacity for logical thought, reflection, explanation and justification.

- Productive disposition - habitual inclination to see STEM as sensible, useful and worthwhile, coupled with a belief in diligence and one's own ability to solve technology or engineering problems.

A strong ETE curriculum will help students make progress at all five levels. Thus, it is important to consider each of these elements and learning theories that 
describe their acquisition. In the sections that follow, we will describe more concrete actions that ETE designers can use to develop more effective learning environments for each element.

\section{ENGINEERING AND TECHNOLOGY EDUCATION LEARNING THEORIES}

There are several broad theories of learning to consider that highlight some of the major outcomes from the learning sciences. Within each broad learning theory, there are more detailed theories of particular factors that influence learning, but here we focus only on the broad theories and the key distinctions they raise for the ETE teacher and designer.

One can roughly organize the components to be learned from more micro components (a large number of small pieces to be learned that are each executed quickly in time during problem-solving) to more macro components (a smaller number of larger pieces to be learned that are applied more pervasively during problem-solving). For example, there are many simple procedures to learn, each of which might only take a second to execute, whereas there are a few productive dispositions that need to be active through a potentially multiple-week-long process of solving a complex engineering problem. Similarly, one can organize learning theories in terms of having a more micro (short time scale focus on micro features of behavior) vs. macro (longer time scale focus on macro features of behavior) perspective (see Figure 1). This difference is more heuristic/approximate than absolute in that all of the theories make some contact with all of the components. However, a clear point of emphasis exists within each theory.

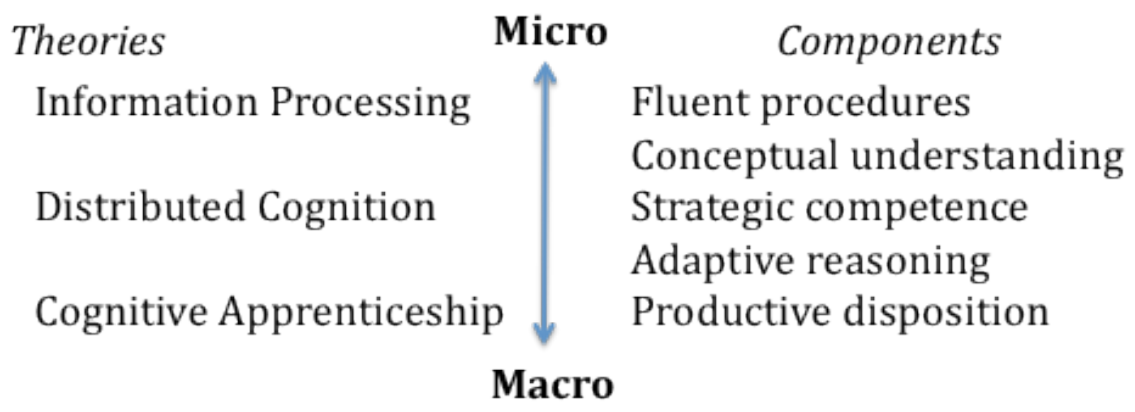

Figure 1. Micro to macro organization of learning theories and components of competent behavior in ETE.

INFORMATION PROCESSING (COGNITIVE) THEORIES OF LEARNING

One of the key insights of Information Processing theory is that complex tasks must be decomposed into informational components that are encoded, stored and processed, and fundamental cognitive limitations exist at each step that influence 
performance and learning. The mind, like a computer, does not have infinite capacity. A general flow of information is shown in Figure 2.

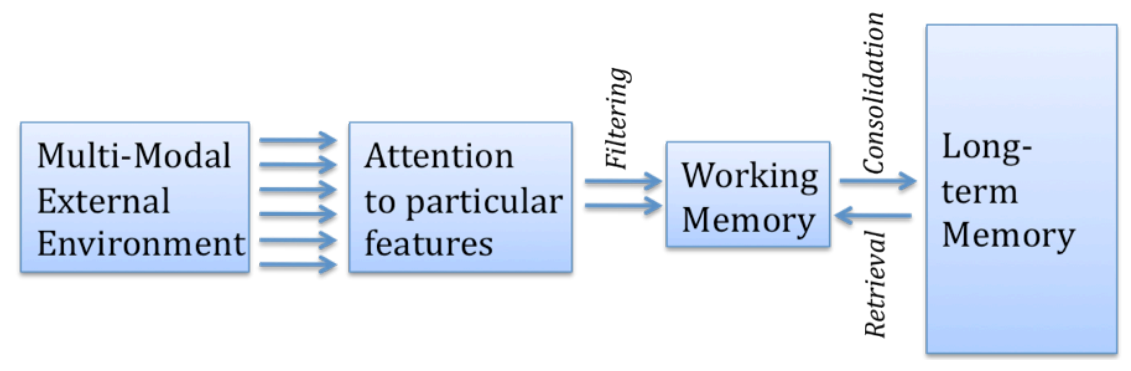

Figure 2. Flow of information from the environment into the mind.

\section{Attention issues}

The problem-solver, especially in more complex engineering and technology settings, sits in a rich environment with all kinds of sensory signals impinging on his/her body (sights and sounds most importantly, but also smell, touch, temperature, pain and hunger). Well-practiced, automatic skills can make some use of much of this information, but more conscious, deliberate problem-solving depends on using information in working memory. The problem-solver actively selects which information to encode into working memory via an attentional filter: only information that is attended is moved initially to working memory, and only a very small bandwidth of information that is perceived can be attended. The mind appears to attend to locations and modalities one at time, but can switch rapidly between locations and modalities (Wickens \& McCarley, 2008).

Novices often do not know what information to attend in a complex environment, and so the instructional designer and teacher must support the learner in attending to the right features at the right time. This might involve simplifying the environment to remove less relevant features, making critical features more salient, or bringing features closer together that must be encoded immediately to solve a problem (Wickens, 2008; van Merrienboer \& Sweller, 2005). But note that learners will have trouble moving from a very simplified learning environment to the real performance environment if the information found in the simplified environment is perceptually different from the real environment and different information encoding skills are required.

Simply pointing out critical features to encode by itself can produce large speedups in learning because feature noticing can be subtle. For example, the skill of chicken sexing (determine a day-old chick's sex by visual inspection) used to take thousands of hours to perfect, but was later learned in a matter of a few hours once learners were explicitly told which features were important to encode (Biederman \& Shiffrar, 1987). Closer to ETE, Kellman, Massey and Son (2010) found that training middle and high school students in mathematics classes to 
recognize patterns and fluently extract meaningful perceptual structures in mathematics problems greatly improved equation solving performance and solving novel problems.

\section{Working memory issues}

Moving information into attention is a first step, but not the last one in terms of information processing. In addition to limitations on how much can be attended at once, working memory is extremely limited in capacity - approximately four independent visual/spatial items and four independent verbal/acoustical items (Baddeley, 2003). Thus, as problem-solvers attend to new things, old things are lost from working memory; they must be mentally rehearsed (or reexamined to reencode them) to be kept in working memory over time.

With experience, problem-solvers can 'chunk' combinations of information so that these familiar combinations only consume one item, effectively increasing working memory capacity in that familiar situation-for example, a chess expert can remember a whole board because sets of pieces can be grouped into familiar chunks, but a chess novice is stuck thinking about each piece on its own (Chase \& Simon, 1973). Similarly, complex devices to a novice are overwhelming to remember because the novice cannot encode the subsystems of the device in terms of familiar groupings (Moss, Kotovsky \& Cagan, 2006).

This severe capacity limitation on working memory has a number of implications for the instructional designer or teacher, especially because reflection by the learner on the task or situation, thought to be useful for learning, also relies on this same limited working memory capacity (van Merrienboer \& Sweller, 2005). First, it is important to think through how many components the task being performed requires for a problem-solver to consider simultaneously in working memory (called the intrinsic cognitive load). It is important not to overwhelm the learner, taking into account the chunks that a learner is likely to already have. The peak cognitive load moment in a task is when errors are most likely to occur (Carpenter, Just and Shell, 1990). Addressing this issue might involve using familiar situations when first introducing procedures/tasks having a higher intrinsic load.

Second, it is important to find and reduce additional features of the learning situation that might be adding to working memory requirements (called the extrinsic cognitive load). For example, cluttered displays often imply that learners must keep track of where key information is being kept. Somewhat counterintuitively, giving learners a very specific result to compute in an example produces a higher cognitive load than just asking students to compute a variety of results in the same situation because the specific goal must be stored in working memory (van Merrienboer \& Sweller, 2005) - as a result, the specific goal situation produces more errors and reduces learning. Similarly, initially studying examples that show the solution process produces better learning outcomes than having students immediately solve problems on their own because the cognitive load of solving problems is higher than that associated with studying worked examples. 
CHRISTIAN D. SCHUNN \& ELI M. SILK

\section{Consolidation/fluid fact retrieval}

As noted above, the working memory requirements of a situation are reduced when the problem-solvers can encode the situation in terms of larger familiar chunks. Where do these chunks come from? The chunks reside in long-term memory, which has essentially unlimited capacity (i.e., it never gets 'full'), but information is stored relatively slowly in working memory through a process called consolidation. In addition, problems may occur in retrieving the right chunks at the right time (i.e., stored information can get lost in the sea).

Expert performance involves having rapid access to relevant long-term memory chunks and this rapid access is built up gradually through repeated exposure. Here there is no free lunch, no cognitive shortcut (Anderson \& Schunn, 2000). Rather, a relatively simple relationship exists by which each exposure slowly increases the probability of retrieving the information later and decreases the rate at which information is forgotten. There is one important caveat: studying information repeatedly spread out over time, rather than cramming, can have a large effect on how quickly information is forgotten (Pavlik \& Anderson, 2005). So, for foundational information that is to be used in subsequent units or courses, it is very useful to revisit that information repeatedly at multiple points in the curriculum, spaced out over time.

\section{Proceduralization}

Chunking and storage in long-term memory is what happens to facts or memories for particular task arrangements and outcomes. A different kind of learning happens with skills. Here, information moves from being represented as facts to being represented as actions, a process called proceduralization. As a simple example, learning to drive a car begins with being told or reading about the steps involved. Students might be able to recite what the steps are, but they cannot actually consistently execute the steps until they have practiced the steps repeatedly. Over time, with enough practice, a problem-solver might actually lose the ability to recite the steps involved verbally because he or she no longer relies on that form of knowledge.

Similar to consolidation, proceduralization is a slow learning process with no magic bullets other than finding ways for students to more consistently practice only relevant steps. If a problem-solver wants to become fast and accurate at a procedure, hours of practice are required. Interestingly, there does not appear to be any point at which improvements stop with practice: even after thousands of hours of practice, people appear to keep getting faster with increasing practice, although of course the amount of improvement with each hour of practice diminishes (Anderson, Fincham \& Douglass, 1997).

Proceduralization reduces working memory requirements because elements of the procedure do not need to be represented in working memory. Proceduralization does not by itself automatize the skill in that the skill, when first proceduralized, depends on explicit goals found in working memory and can be easily stopped or 
adapted through metacognitive reflection. However, with enough practice, the skills become automatic in the sense that they do not require any attentional resources to start the procedure, but they also cannot be easily stopped or adapted. For example, adults automatically read words as soon as they appear and cannot prevent themselves from reading the words. Sometimes problem-solvers need to complete multiple skills simultaneously; this dual task activity becomes more feasible when at least one of the skills has been practiced to the point of automaticity.

\section{Prior knowledge/misconceptions}

The previous analysis gives the sense of knowledge elements in isolation, each practiced in isolation. However, there are connections, particularly with respect to concepts. Cognitive research has found that one of the strongest predictors of how well a student is likely to learn something is how the new learning is related to what the student already knows and how their prior knowledge is organized (National Research Council, 1999, 2007). If the concepts to be learned and the way they are organized match neatly with a learner's pre-existing knowledge base, then the learning is likely to be smooth and rapid. However, in science and engineering, students often lack relevant conceptual frameworks or have frameworks that are not developed enough to support new learning adequately. If students cannot relate new information to a meaningful framework, they will probably resort to memorizing terms that will be quickly forgotten or that will remain in isolation, unable to be connected to other knowledge or applied when relevant.

ETE, including supporting science education, often extends everyday understanding to new levels that cannot be seen directly or experienced in everyday life. For example, much of biology and chemistry involves learning about entities and processes at a microscopic level. In biology, many students correctly associate properties like breathing, growth and reproduction with living organisms, but their understanding of these properties is based on their everyday experience. They understand something like breathing as taking air in and out through one's mouth or nose, and the need to do so is self-evidently obvious. This is correct as far as it goes, but a scientific understanding delves much deeper and explains these properties in terms of exchanges of gases that are required at the cellular level for cells to engage in the metabolic processes that support life. The way a person, a fish and a tree "breathe" may appear quite different on the surface, but the processes of cellular respiration unify and explain the common need to exchange gases and help us understand how different groups of organisms meet that need (see Chapter 5 for a more detailed discussion of the transfer of conceptual knowledge). To make sense of this, students must add new levels of concepts and explanatory systems to their understanding of the natural world and then work out how those levels are connected to their pre-existing views of the world (Smith, Maclin, Grosslight \& Davis, 1997).

While some elements of ETE involve concepts very foreign to students, some concepts are misleadingly familiar to students. Through everyday informal interaction in the world, students sometimes develop misconceptions of how the 
natural and man-made world around them actually works. For example, in physics, most students have very serious misconceptions that are in direct opposition to Newton's Laws: students strongly believe that a table does not push up on a book sitting on it and they strongly believe that objects stay in motion only because a force continues to be applied to it (Clement, 1982). Because these informal understandings have been developed through years of experience, they are incredibly resistant to change through instruction. Instruction that ignores these misconceptions tends to fade quickly, leaving only the misconceptions in the learner's head, whereas instruction that evokes and directly attacks these misconceptions has significantly improved student learning (Hammer \& Elby, 2003; Kim \& Pak, 2002).

Because these connections and reparation of existing knowledge are so crucial to learning, teaching and learning strategies that involve sense-making by the students have often been found to be especially effective. For example, encouraging students to self-explain during reading (i.e., monitor whether they understand what was read, make connections between paragraphs or between text and diagrams, make predictions and provide explanations for the provided information) can lead to great improvements in understanding the text, in retaining the material and afterwards the ability to apply the information later in new contexts (Chi et al., 1989). See Chapter 5 for a broader analysis of factors that influence this kind of learning.

\section{Cognitive task analysis}

Practice is the key to expert performance. But it is critically important that time be devoted to practicing all critical skills in the goal task. The benefits of practice are very specific to the particular skills that were practiced. For this reason, it is important to do a cognitive task analysis of the steps involved in completing a task. Note the term 'cognitive' in cognitive task analysis. A non-cognitive task analysis involves analyzing the external steps involved in completing a task. A cognitive analysis includes the mental steps required in the task, including mental calculations and retrievals from long-term memory.

A cognitive task analysis can be difficult to complete, especially by experts who have proceduralized many elements of the task, thereby losing the ability to articulate the procedures they execute verbally. So, one cannot simply interview experts to determine required skills. Instead, one must observe experts at work, perhaps having them give a think-aloud protocol that offers some access to the contents of verbal working memory (Ericsson \& Simon, 1983). From this trace of external actions and contents of verbal working memory, one must infer the steps taken by the problem-solver.

Why is it worth the effort to do a cognitive task analysis? First, it clarifies what skills and concepts must be practiced, which makes it clearer as to what kinds of practice tasks should be assigned to ensure that all components skills and concepts receive some practice. Different problems can involve different subsets of skill 
application. As a simple example, different subtraction problems may or may not involve particular borrowing steps.

Second, the cognitive task analysis creates some opportunities for improving the efficiency of learning with intelligent learning systems that track student performance at the cognitive components level. Solving problems can take considerable learning time. If a given student has already made considerable progress on skills $\mathrm{A}, \mathrm{B}, \mathrm{C}$ but not skills $\mathrm{D}$, E, less efficient use of learning time would be made to present more problems involving $\mathrm{A}, \mathrm{B}, \mathrm{C}$ or $\mathrm{A}, \mathrm{B}, \mathrm{E}$ and more efficient use of learning time to present problems involving just $D$, E. Cognitive tutors that present problems in exactly this way (in addition to providing immediate feedback on which cognitive steps were incorrectly completed) can take students to the same learning outcomes in much less time (Anderson, Corbett, Koedinger and Pelletier, 1995).

Third, important transfer across tasks can happen at the level of shared cognitive components. So, learners can be given simplified learning tasks (to simplify attentional demands, to reduce working memory requirements and to focus time on unlearned elements) but still transfer to real tasks if the tasks share important cognitive components. For example, Klahr and Carver (1988) conducted a cognitive task analysis of program debugging skills. They then explicitly taught these skills to students, which they quickly mastered and practiced. Then, in a test of transferring these skills to a completely different task that should have shared important cognitive elements of debugging, Klahr and Carver found that students were much better at debugging errors in written instructions, such as arranging items, following map routes, or allocating resources.

\section{Summary of information processing}

From an information processing point of view, it is important to determine the information that students need to be processing, considering perceptual encoding, working memory, and long-term conceptual and skill components. Further, this analysis must examine both eventual fluent problem-solving and the learning environment. Learning takes place through accurate focus on and practice with the critical elements. Given the frequent complexity of ETE, it is easy to overlook critical skills or concepts without a careful cognitive task analysis conducted by the designer of the ETE learning environment.

\section{DISTRIBUTED COGNITION LEARNING THEORIES}

Information processing theories place a strong emphasis on the mental workings of individual minds. Distributed cognition generalizes the information processing theory framework to include the physical environment around the learner, including interactions with other problem-solvers. As noted in the previous section, cognitive load is a key bottleneck to complex problem-solving and learning. External tools and other problem-solvers in the environment can be used to share the load. For example, in a plane cockpit, the pilot uses dials to help remember the state the 
plane is in, uses the co-pilot to help run through check-lists before take-off, and even uses simple perceptual features of dials and indicators to compute simple computations about whether to change the plane's speed (Hutchins, 1995).

This distributed extension of information processing applies to ETE in a number of different ways. First, engineering and technological problem-solving tend to involve working with complex external environments and groups of individuals working together, rather than individuals working alone or doing purely mental calculations. Thus, it is not necessary for ETE learners to be able to do complex tasks purely in their heads because it is unlikely that they will encounter that performance standard later.

Second, problem-based learning is often implemented as group-work. By assigning different individuals different roles (including monitoring overall performance or learning of individuals), the overwhelming complexity of many ETE learning tasks becomes manageable. However, it is important that the tasks be divided such that the cognitive load is decreased rather than increased. In tightly coupled tasks distributed across individuals, each problem-solver has the additional challenge of having to keep track of their partner's task state as well as their own task state. Such distribution increases rather than decreases each learner's cognitive load. It is better to have multiple learners work on more independent tasks or have them attend to the same task state but perhaps from different perspectives (Prince, 2004).

Third, engineers and technologists use thinking tools, often called models, that distribute thinking in another way and this requires an additional strand for learning. Models are tools or formalisms that represent aspects of some external situation for a particular purpose. Common examples from ETE include graphs, equations, physical prototypes, computer-aided design models and design analysis tools. A given situation could be represented by any and all of these examples (Gainsburg, 2006). Each representational tool has strengths and weaknesses. Which model or combination of models should be used at any given time depends upon the problem-solver's purposes. Even within a given type of model (e.g., physical prototype), there are choices as to which features to include and which to exclude (e.g., color, moving parts, structural strength).

This last element is a critical component of strategic competence (one of the key components from Figure 1) - the ability to formulate, represent and solve complex STEM problems. Complex ill-defined problems (as frequently occurs in engineering and technology problem-solving) can move from being nearly unsolvable to trivial through the selection of the appropriate representational tools (Kaplan \& Simon, 1990).

But modeling, as a skill, can be a challenge to learners. Students initially do not see models as representational — standing for something else — but rather just things on their own, serving no greater purpose. Further, students are usually given models rather than being allowed to modify and strategically select models, thereby undercutting the development of strategic competence. 
Models \& modeling perspective and model-eliciting activities

In the mathematics education and engineering education communities, a new general approach to instruction is developing called the models \& modeling perspective (M\&M; Lesh \& Doerr, 2003), focusing on the complexities and benefits of models as a particular kind of distributed cognition. Whereas the information processing theoretical perspective often led to careful arrangements of problem-solving activity, the M\&M perspective has advocated a different sort of instructional activity exemplified by model-eliciting activities (MEAs; Hamilton et al., 2008). MEAs are a form of problem-based learning well matched to ETE in which the problem-solvers are asked to produce conceptual tools for constructing, describing, or explaining meaningful situations. This process of developing such a conceptual tool typically involves a series of express-test-and-revise cycles. The iterative model development process helps students both to develop more sophisticated ways of understanding important conceptual ideas and to acquire a productive disposition toward thinking about their own ideas or models of situations as tools - useful and adaptable for solving real problems (Lesh \& Lehrer, 2003).

MEAs have been developed for $\mathrm{K}-12$ and undergraduate mathematics, technology and engineering education (e.g., http://modelsandmodeling.net). A number of well-defined principles for developing MEAs exist (Lesh et al., 2000). In addition, MEAs are typically contextualized around a problem where students have to sort through a wide range of quantitative data and develop a procedure or process for a client. For example, the Nano Roughness MEA (Moore \& DiefesDux, 2004) challenges students to quantify the roughness of nanoscale materials that a biomedical company is considering to use for artificial hip joints. One principle of MEAs is the Model-Construction Principle - that the problem requires students to create a mathematical model of the situation. In the Nano Roughness MEA, students examine atomic force microscope (AFM) images that provide quantitative data on the surface height of materials and use this information to generate their own procedures for quantifying roughness, of which there are many possibilities.

MEAs can result in a form of local conceptual development in which students make progress in a particular situation with the specific tools available in a way that parallels larger developmental processes of more general conceptual structures (Lesh \& Harel, 2003). Thus, MEAs provide students with opportunities to develop their ways of thinking about central conceptual ideas within realistic problemsolving contexts.

We have begun to explore in our own work with robotics technology classes in middle schools how the M\&M perspective and MEAs can provide a sound theoretical basis for improved learning (Silk et al., 2010). For example, we provide middle-school aged students with the case of a robotics team that programs synchronized dancing Lego robots. The fictional team receives different dance routines from fans via the Internet. The problem is to program these various dance routines in a way that different sized robots will dance in synchrony. The students' 
task is to develop a script that the fictional team can use to program robots for these arbitrary scripts quickly and accurately. Since the situation is open-ended, the students must develop their own physical and mathematical models to determine how different robotics moves vary across different sized robots and then use these models to develop the script. Here, students are thinking about specific proportional relationships in the problem, and through a model refinement process, they may further improve their mathematical concept of proportionality or their robotics concept of proportional control.

\section{COGNITIVE APPRENTICESHIP LEARNING THEORIES}

All areas of professional education, including engineering and technology education, have had a long history of apprenticeship approaches to learning. At school, students were meant to learn the underlying principles and most fundamental skills/knowledge (writing, mathematics, science), and then through internships, co-op experiences, or on-the-job training, learn the 'real' skills of the discipline. Even instruction that was intended for all children, rather than just the next generation of a particular profession, has been influenced somewhat by applying lessons from apprenticeship learning to instruction.

\section{Traditional apprenticeship learning}

Analysis of learning in traditional apprenticeship situations noticed important common instructional features. One important feature is that much early apprenticeship learning involves observation by the apprentice of more expert performance, rather than immediately having the learner engage in problemsolving, read about problem-solving, or hear lectures about problem-solving (Lave, 1988).

The second important feature is the expert provides many supports for the learner during problem-solving, called scaffolds. For example, the expert may provide hints or do parts of the task, leaving the first or last pieces for the learner. Gradually over time, these scaffolds are removed, a process called fading (Vygotsky, 1978). A number of intelligent computer tutoring systems have successfully used this scaffolding and fading approach to speed up learning (Renkl, Atkinson \& Grosse, 2004), including of engineering materials (Reisslein, Sullivan $\&$ Reisslein, 2007).

From such apprenticeship experiences related to ETE, students develop a productive disposition towards STEM (the last key component listed in Figure 1). Because they see performance of STEM in action, the usefulness of STEM components is made very persuasively. Observation of a diligent expert provides a good model for work ethics in STEM. Finally, the scaffolding and fading help to ensure that students develop and maintain high self-efficacy about their own ability to solve STEM problems. 


\section{Cognitive apprenticeship learning}

Although apprenticeship learning does produce expert performance, the path is often quite slow, and the learning that results can be somewhat fragile or specific to the particular learning environment of training (Suchman, 1987). This last element was particularly troubling for applications to school environments, which could not be made like work environments for large numbers of students. Information processing theorists examined apprenticeship learning and proposed a hybrid theory called Cognitive Apprenticeship that was meant to speed up and make the transfer from schooling to other settings more robust (Collins, Brown \& Holum, 1991).

One element of cognitive apprenticeship is that the expert tries to make all aspects of the task visible to the learners, which further supports the learner's ability to engage in more adaptive reasoning across settings (the fourth key component from Figure 1). In traditional apprenticeship, it is up to the learner to figure out which features to encode and what steps are going on. For ETE, in which many steps are mental and abstract, traditional apprenticeship leaves the learner with a huge inference task. To make aspects of the task more visible to the learner, an instructor might think aloud during problem-solving. For example, in mathematics instruction, Schoenfeld (1987) found it particularly useful to show students the heuristics that mathematicians use for selecting among possible problem-solving steps rather than just the formal steps found in particular algorithms. In addition, an instructor might ask learners to alternate between being a critic or guide and a learner or doer receiving critical comments. Reciprocal teaching is an approach that has used this element of cognitive apprenticeship to great effect in reading instruction (Palinscar \& Brown, 1984) and physics instruction (Reif, 1999).

A second element of cognitive apprenticeship is the importance of varying situations such that transfer to new situations will become more likely. Preferably this varying of situations is done by gradually increasing the complexity of the tasks and the diversity of the skills and concepts required to complete the task. That is, rather than simply working on complete problems as they come and providing scaffolding for the students, the order of selected problems is chosen purposefully with respect to complexity and diversity of skills and concepts (Collins, Brown \& Holum, 1991).

However, the sequencing of problems does not mean instruction should begin with micro-problems that are completely divorced from real problem situations because the students will then lose the connection between what they are learning and the situations to which these skills and concepts should apply. Instead, instruction should go from global to local so problem-solvers can see the relevance. That is, a full problem can be introduced, but then instruction can transition to solving components of the larger problem. This issue of global/local is particularly applicable to problem-based learning approaches used in ETE. Rich problems can be attempted and yet students can practice critical component skills in effective 
order by supporting the transition from the larger problem to the component subproblems.

For example, in our synchronized dancing robots problem described earlier, we can present the larger synchronized robots problem to students at the very beginning of a long sequence of lessons and then help the students break down the larger program into components, such as linear distance, linear speed, turn amount and turn speed. Each of these components can be divided further into measurement and programming tasks. But the students 'see' the larger problem at the very beginning, rather than beginning the unit with a discussion of measuring linear distances with robots, which the students see as an odd task out of context. There is now emerging evidence that providing a greater 'need-to-know' enhances learning in STEM (Mehalik, Doppelt \& Schunn, 2008).

Overall, cognitive apprenticeship approaches support the development of adaptive reasoning in problem-solvers by encouraging students to reflect on the skills and strategies involved in solving larger, more complex problems.

\section{CONCLUSION}

Successful problem-solving in engineering and technology settings requires attending to five larger elements in the problem-solver: procedural fluency, conceptual understanding, strategic competence, adaptive reasoning and productive disposition. These five elements are not developed quickly and easily, and learning environments must be carefully organized across years of instruction to meet this challenge.

Given the complexity of what must be learned, it is not surprising that a range of learning theories must be used to explain how this learning happens and what environmental features best support it. As a rough heuristic, we have organized the learning goals from more micro elements to more macro elements, and have then shown how different learning theories connect to these elements. But the mapping is certainly complex and much research remains to be done. In the meanwhile, we strongly encourage active sense-making by the reader in terms of trying to apply the contents of this chapter to their own ETE setting. 
LEARNING THEORIES FOR ETE

\section{REFERENCES/BIBLIOGRAPHY}

Anderson, J. R., Bothell, D., Byrne, M., \& LeBiere, C. (2004). An integrated theory of the mind. Psychological Review, 111(4), 1036-1060.

Anderson, J. R., Corbett, A. T., Koedinger, K. R., \& Pelletier, R. (1995). Cognitive tutors: Lessons learned. The Journal of the Learning Sciences, 4(2), 167-207.

Anderson, J. R., Fincham, J. M., \& Douglass, S. (1997). The role of examples and rules in the acquisition of a cognitive skill. Journal of Experimental Psychology-Learning Memory and Cognition, 23(4), 932-945.

Anderson, J. R., \& Schunn, C. D. (2000). Implications of the ACT-R learning theory: No magic bullets In R. Glaser (Ed.), Advances in instructional psychology (Vol. 5, pp. 1-33). Mahwah, NJ: Erlbaum.

Baddeley, A. (2003). Working memory: Looking back and looking forward. Nature Reviews Neuroscience, 4(10), 829-839.

Biederman, I., \& Shiffrar, M. M. (1987). Sexing day-old chicks: A case study and expert systems analysis of a difficult perceptual-learning task. Journal of Experimental Psychology: Learning, Memory, and Cognition, 13(4), 640-645.

Borrego, M. (2007). Conceptual difficulties experienced by trained engineers learning educational research methods. Journal of Engineering Education, 96(2), 91-102.

Carpenter, P. A., Just, M. A., \& Shell, P. (1990). What one intelligence test measures: A theoretical account of the processing in the Raven Progressive Matrices Test. Psychological Review, 97, 404431.

Chase, W. G., \& Simon, H. A. (1973). Perception in chess. Cognitive Psychology, 4, 55-81.

Chi, M. T. H., Bassok, M., Lewis, M. W., Reimann, P., \& Glaser, R. (1989). Self-explanations: How students study and use examples in learning to solve problems. Cognitive Science, 15, 145-182.

Clement, J. (1982). Students' preconceptions in introductory mechanics. The American Journal of Physics, 50(1), 66-71.

Collins, A., Brown, J. S., \& Holum, A. (1991). Cognitive apprenticeship: Making thinking visible. American Educator, 15(3), 6-11, 38-46.

Ericsson, K. A., \& Simon, H. A. (1993). Protocol analysis: Verbal reports as data (2nd ed.). Cambridge, MA: MIT Press.

Gainsburg, J. (2006). The mathematical modelling of structural engineers. Mathematical Thinking and Learning, 8(1), 3-36.

Geary, D. C., Boykin, A. W., Embretson, S., Reyna, V., Siegler, R., Berch, D. B., \& Graban, J. (2008). Report of the task group on learning processes. Washington, DC: U.S. Department of Education.

Hamilton, E., Lesh, R., Lester, F., \& Brilleslyper, M. (2008). Model-eliciting activities (MEAs) as a bridge between engineering education research and mathematics education research. Advances in Engineering Education, 1(2), 1-25.

Hammer, D. \& Elby, A. (2003). Tapping epistemological resources for learning physics. Journal of the Learning Sciences, 12(1), 53-90.

Hutchins, E. (1995). How a cockpit remembers its speeds. Cognitive Science, 19(3), 265-288.

Kaplan, C. A., \& Simon, H. A. (1990). In search of insight. Cognitive Psychology, 22, 374-419.

Kellman, P. J., Massey, C. M., \& Son, J. Y. (2010). Perceptual learning modules in mathematics: Enhancing students' pattern recognition, structure extraction, and fluency. Topics in Cognitive Science, 2(2), 285-305.

Kilpatrick, J., Swafford, J., \& Findell, B. (Eds.). (2001). Adding it up: Helping children learn mathematics. Washington, DC: National Academies Press.

Kim, E., \& Pak, S. J. (2002). Students do not overcome conceptual difficulties after solving 1000 traditional problems. American Journal of Physics, 70, 759-765.

Klahr, D., \& Carver, S. M. (1988). Cognitive objectives in a LOGO debugging curriculum: Instruction, learning, and transfer. Cognitive Psychology, 20, 362-404. 


\section{CHRISTIAN D. SCHUNN \& ELI M. SILK}

Knowlton, B. J., Mangels, J. A., \& Squire, L. R. (1996). A neostriatal habit learning system in humans. Science, 273, 1399-1402.

Lave, J. (1988). Cognition in practice: Mind, mathematics and culture in everyday life. Cambridge, MA: Cambridge University Press.

Lesh, R., \& Doerr, H. (2003). Beyond constructivism: A models \& modeling perspective on mathematics teaching, learning, and problems solving. Mahwah, NJ: Lawrence Erlbaum.

Lesh, R., \& Harel, G. (2003). Problem solving, modeling, and local conceptual development. Mathematical Thinking and Learning, 5(2\&3), 157-189.

Lesh, R., Hoover, M., Hole, B., Kelly, A., \& Post, T. (2000). Principles for developing thoughtrevealing activities for students and teachers. In A. Kelly \& R. Lesh (Eds.), Handbook of research design in mathematics and science education (pp. 591-646). Mahwah, NJ: Lawrence Erlbaum Associates.

Lesh, R., \& Lehrer, R. (2003). Models and modeling perspectives on the development of students and teachers. Mathematical Thinking and Learning, 5(2\&3), 109-129.

Mehalik, M. M., \& Doppelt, Y., \& Schunn, C. D. (2008). Middle-school science through design-based learning versus scripted inquiry: Better overall science concept learning and equity gap reduction. Journal of Engineering Education, 97(1), 71-85.

Moore, T. J., \& Diefes-Dux, H. A. (2004). Developing Model-Eliciting Activities for undergraduate students based on advanced engineering context. Proceedings of the Thirty-Fourth ASEE/IEEE Frontiers in Education Conference. Savannah, GA. Retrieved from http://fie-conference.org/fie2004/index.htm

Moss, J., Kotovsky, K., \& Cagan, J. (2006). The role of functionality in the mental representations of engineering students: Some differences in the early stages of expertise. Cognitive Science, 30(1), 6593.

John, D., Bransford, J. D., Brown, A. L., \& Cocking, R. R. (Eds.). (1999). How people learn: Brain, mind, experience, and school. Washington, DC: National Academies Press.

Duschl, R. A., Schweingruber, H. A., \& Shouse, A. W. (Eds.). (2007). Taking science to school: Learning and teaching science in grades K-8. Washington, DC: The National Academies Press.

Palincsar, A. S., \& Brown, A. L. (1984). Reciprocal teaching of comprehension-fostering and comprehension-monitoring activities. Cognition and Instruction, 1(2), 117-175.

Pavlik, P. I., \& Anderson, J. R. (2005). Practice and forgetting effects on vocabulary memory: An activation-based model of the spacing effect. Cognitive Science, 29(4), 559-586.

Prince, M. (2004). Does active learning work? A review of the research. Journal of Engineering Education, 93(3), 223-231.

Reif, F., \& Scott, L. A. (1999). Teaching scientific thinking skills: Students and computers coaching each other. American Journal of Physics, 67(9), 819-831.

Reisslein, J., Sullivan, H., \& Reisslein, M. (2007). Learning achievement and attitudes under different paces of transitioning to independent problem solving. Journal of Engineering Education, 96(1), 4555.

Renkl, A., Atkinson, R. K., \& Grosse, C. S. (2004). How fading worked solution steps works - a cognitive load perspective. Instructional Science, 32(1-2), 59-82.

Schoenfeld, A. H. (1987). Cognitive Science and Mathematics Education. Hillsdale, NJ: Erlbaum.

Silk, E. M., Higashi, R., Shoop, R., \& Schunn, C. D. (2010). Designing technology activities that teach mathematics. The Technology Teacher, 69(4), 21-27.

Singley, M. K., \& Anderson, J. R. (1989). The transfer of cognitive skill. Cambridge, MA: Harvard Press.

Smith, C., Maclin, D., Grosslight, L., \& Davis, H. (1997). Teaching for understanding: A study of students' pre-instruction theories of matter and a comparison of the effectiveness of two approaches to teaching about matter and density. Cognition and Instruction, 15(3), 317-393.

Suchman, L. A. (1987). Plans and situated action: The problem of human-machine communication. New York: Cambridge University Press. 


\section{LEARNING THEORIES FOR ETE}

Thorndike, E. L. (1913). Educational psychology: The psychology of learning (Vol. 2). New York: Teacher's College.

Van Merrienboer, J. J. G., \& Sweller, J. (2005). Cognitive load theory and complex learning: recent developments and future directions. Educational Psychology Review, 17(2), 147-177.

Vygotsky L. S. (1978) Mind in society. In M. Cole, V. John-Steiner, S. Scribner, \& E. Souberman (Eds.), Interaction between learning and development (pp.79-91). Cambridge MA: Harvard University Press. ...

Wickens, C. D. (2008). Multiple Resources and Mental Workload. Human Factors: The Journal of the Human Factors and Ergonomics Society, 50(3), 449-455.

Wickens, C. D., \& McCarley, J. S. (2008). Applied attention theory. Boca Raton, FL: Taylor \& Francis.

\section{AFFILIATIONS}

Christian D. Schunn \& Eli M. Silk

Learning Research and Development Center,

University of Pittsburgh

USA 